\title{
A Unique Case of Unilateral Lower Extremity Sparing Systemic Peripheral Gangrene
}

\author{
Alexey Markelov, ${ }^{1}$ Steven DeFroda, ${ }^{2}$ \\ Leopoldo Baccaro, ${ }^{1}$ and Jamie Bastidas ${ }^{1}$ \\ ${ }^{1}$ Department of Surgery, Easton Hospital, Drexel University College of Medicine, \\ Easton, PA 18042, USA \\ ${ }^{2}$ Drexel University College of Medicine, Philadelphia, PA 19129, USA
}

Correspondence should be addressed to Alexey Markelov, dr.markelov@gmail.com

Received 8 November 2012; Accepted 28 November 2012

Academic Editors: N. Espinola-Zavaleta, L. Masotti, and N. Papanas

Copyright ( $) 2012$ Alexey Markelov et al. This is an open access article distributed under the Creative Commons Attribution License, which permits unrestricted use, distribution, and reproduction in any medium, provided the original work is properly cited.

We present here the case of a 70-year-old female who developed a systemic peripheral gangrene in both of her upper extremities (all fingers) and her right foot due to a severe septic shock requiring a systemic vasopressor therapy. Interestingly, the patient's left foot remained spared from gangrenous changes possibly due to a chronic external iliac artery occlusion and thus the lower concentration of vasopressors in that extremity.

\section{Introduction}

Systemic peripheral gangrene (SPG) is defined as a symmetric ischemia in the absence of a large vessel obstruction in at least two of the following: distal extremities, tip of the nose, ears, and genitals $[1,2]$. It typically occurs in the face of an infectious disease or low flow states such as cardiogenic shock [3]. It can also occur as a result of vascular problems such as Reynaud's, c-protein deficiency, sickle cell disease, and paraneoplastic syndromes [4]. Iatrogenic causes such as the administration of systemic vasopressor in the presence or absence of sepsis have also been shown to cause SPG. Our patient developed gangrenous necrosis in all of the extremities except the left foot. This was a curious finding; however, further investigation revealed that the patient had a chronic occlusion of the left superficial femoral artery. It was hypothesized at the time, and currently believed, that this significant obstruction prevented the "adequate" delivery of vasopressors to her distal lower extremity, preventing excessive vasospasm and subsequent necrosis. A review of the literature does not reveal any similar cases of a patient experiencing SPG with one limb spared secondary to underlying undiagnosed peripheral artery disease.

\section{Case Report}

70-year-old Hispanic female with the past medical history of congenital paralysis below the waste presented with an episode of urinary tract infection caused by $E$. coli. The patient subsequently developed a septic shock with multisystem organ failure and disseminated intravascular coagulation that required a vasopressor therapy. The patient required an administration of high doses (up to $30 \mathrm{mcg} / \mathrm{kg} / \mathrm{min}$ ) of norepinephrine in conjunction with vasopressin during prolonged ICU course. Secondary to that the patient developed a bilateral dry gangrene of all distal phalanges, as well as the gangrene of the distal right foot from tarsal to the metatarsal level (Figure 1).

The left foot, however, remained spared from any ischemic changes (Figure 2). 


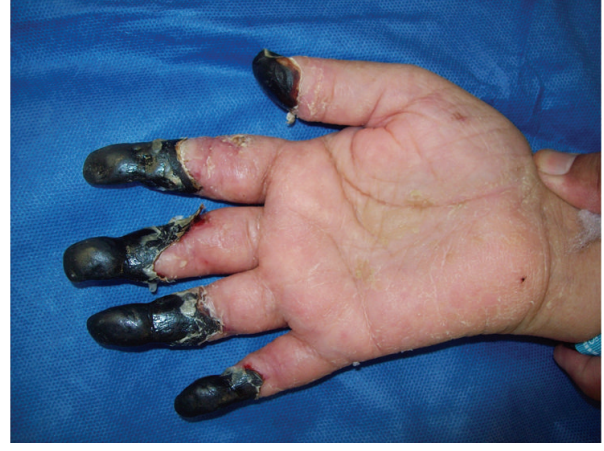

(a)

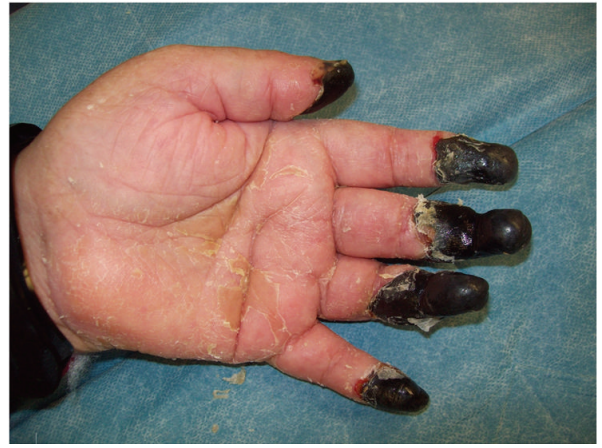

(b)

FIGURE 1: Bilateral peripheral gangrene of upper extremities.

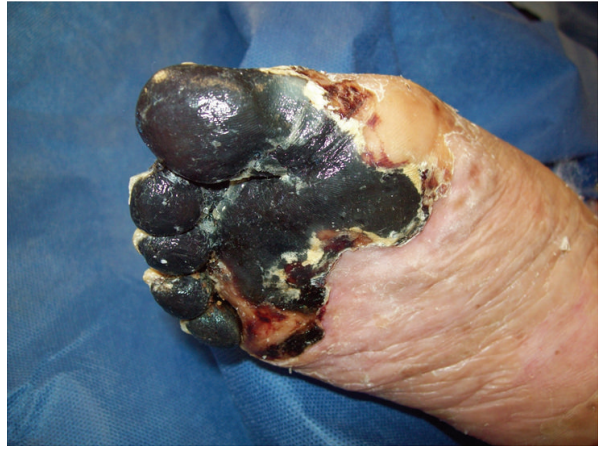

(a)

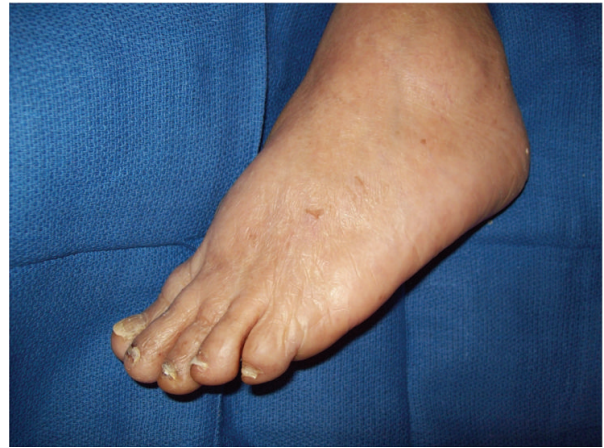

(b)

FIGURE 2: Unilateral lower extremity sparing systemic peripheral gangrene.

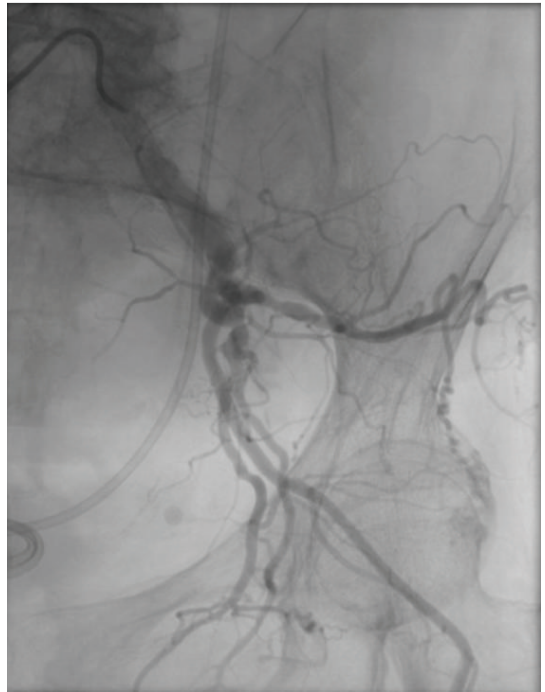

Figure 3: Left lower extremity arteriogram showing the chronic occlusion of external iliac artery.

Subsequent cardiac catheterization study incidentally revealed the chronic occlusion of the left external iliac artery (Figure 3), which most likely prevented the infarct of the left lower extremity. The patient eventually underwent bilateral amputations of all fingers and toe amputations on her right lower extremity.

\section{Discussion}

Symmetrical peripheral gangrene (SPG) is a well-documented but rare clinical syndrome characterized by symmetrical distal ischemic damage leading to gangrene of two or more sites in the absence of a large vessel obstruction or vasculitis. Hutchison first described SPG in 1891 [3]. Although described more than a century ago, most of the cases of SPG have been documented as single case reports. A review of English language medical literature that we conducted did not reveal any similar cases of patient experiencing SPG with one limb spared secondary to underlying undiagnosed peripheral artery disease.

A wide array of infective and noninfective etiological factors has been linked with the development of SPG (Table 1).

The exact pathophysiological mechanism of the vascular occlusion in SPG is uncertain. A low-flow state along with disseminated intravascular coagulation (DIC) is usually present. DIC is an almost universal finding and is probably the final common event in the microvascular insult that gives rise to the typical clinical features of this syndrome. Diagnosis and management of DIC should be guided by basic tests to evaluate the coagulation cascade (PT, PTT, and fibrin 
TABLE 1: Causes of systemic peripheral gangrene.

\begin{tabular}{llll}
\hline & & \multicolumn{2}{c}{ Causes of SPG } \\
Infectious & Pharmacologic & Systemic \\
\hline Bacterial sepsis & Dopamine & Diltiazem & Paraneoplastic syndrome \\
Viral sepsis & Inotropin & Haloperidol & Ergotism \\
& Epoprostenol & Thorazine & Polymyalgia rheumatica \\
& Phenoxybenzamine & Cocaine & Raynaud's phenomenon \\
Rickettsia & Phentolamine & Amphetamine & C protein deficiency \\
& Trimethaphan & Thiopentone & Sickle cell disease \\
\hline
\end{tabular}

split products) and if found, it should be treated early and aggressively. Identification and treatment of the underlying cause is the most important part of the treatment. It is important to remember that vasopressor agents, commonly used in the management of sepsis-induced hypotension, may aggravate SPG.

In conclusion, SPG is a cause of significant morbidity and mortality often requiring multiple limb amputations in the survivors. Thus, early recognition of SPG and its underlying conditions can have a profound impact on the management of the condition and its final outcome.

\section{Disclosure}

All authors are in agreement with the content of this paper. They declare no financial disclosures or conflicts of interests. This paper has not been published previously and it is not under consideration elsewhere.

\section{References}

[1] M. J. Winkler and D. D. Trunkey, "Dopamine gangrene," American Journal of Surgery, vol. 142, no. 5, pp. 588-591, 1981.

[2] M. A. Molos and J. C. Hall, "Symmetrical peripheral gangrene and disseminated intravascular coagulation," Archives of Dermatology, vol. 121, no. 8, pp. 1057-1061, 1985.

[3] J. N. Goodwin and T. V. Berne, "Symmetrical peripheral gangrene," Archives of Surgery, vol. 108, no. 6, pp. 780-784, 1974.

[4] T. T. Knight Jr., S. V. Gordon, J. Canady, D. S. Rush, and W. Browder, "Symmetrical peripheral gangrene: a new presentation of an old disease," American Surgeon, vol. 66, no. 2, pp. 196-199, 2000. 


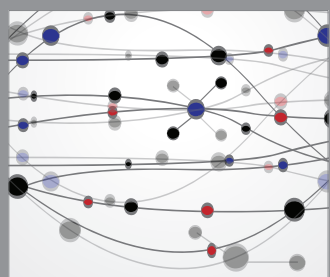

The Scientific World Journal
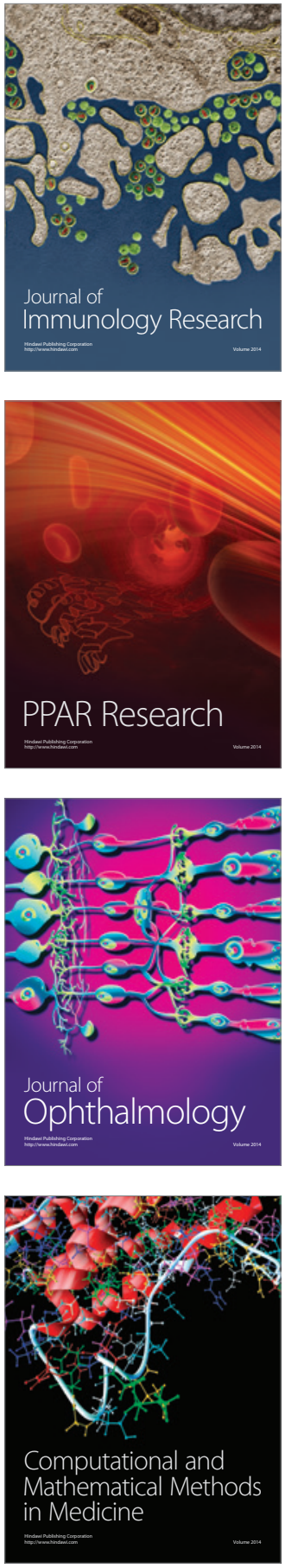

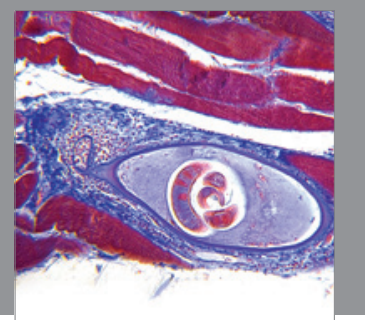

Gastroenterology

Research and Practice
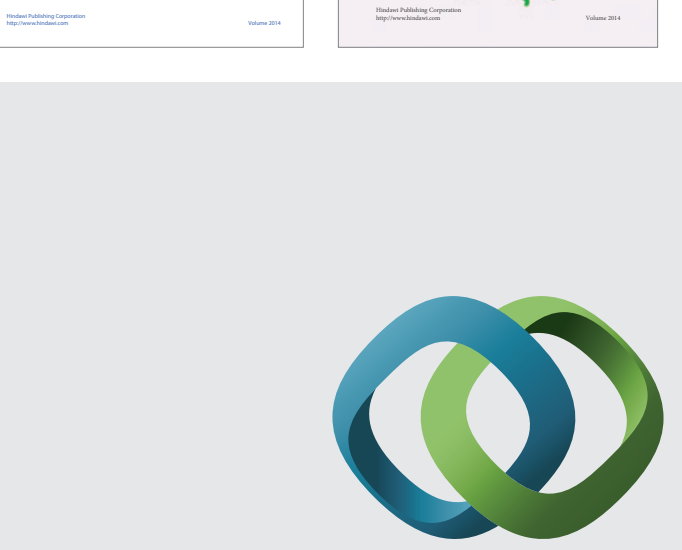

\section{Hindawi}

Submit your manuscripts at

http://www.hindawi.com
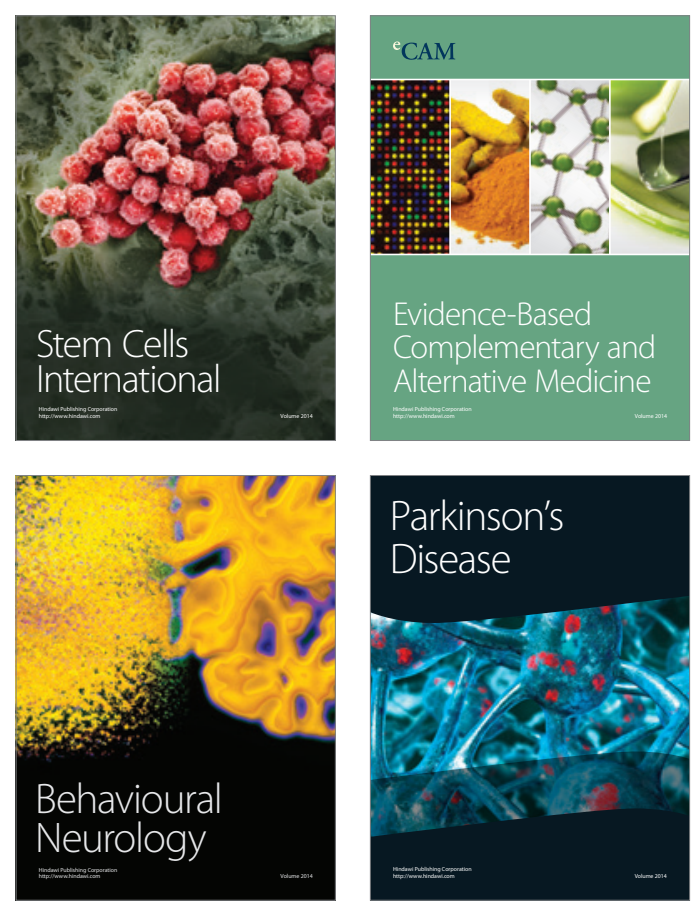

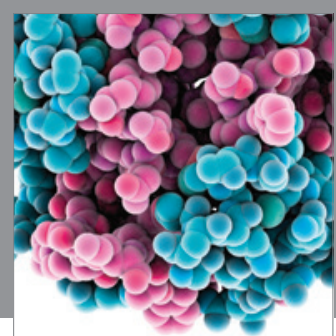

Journal of
Diabetes Research

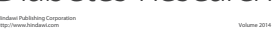

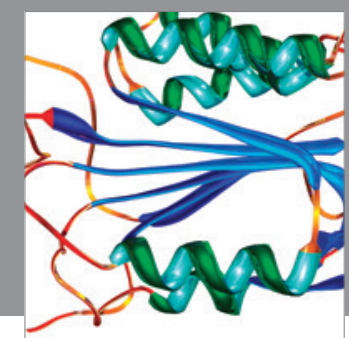

Disease Markers
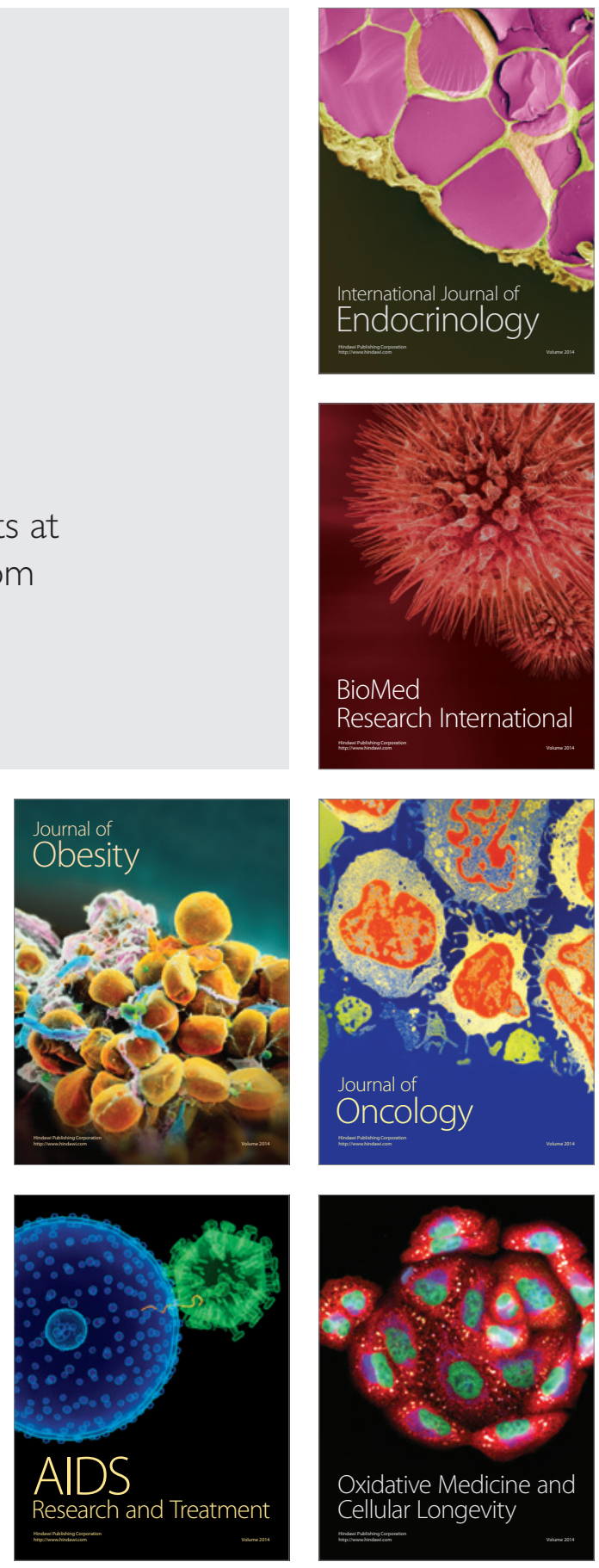